\title{
Event-Related Potential Investigation of the Mechanisms of Memory Encoding in Schizophrenia
} Michael Chih Chien Kuo ${ }^{1, *}$

${ }^{1}$ School of Medical and Health Sciences, Tung Wah College, Hong Kong, China

"Corresponding author: Michael Chih Chien Kuo, Ph.D., Tung Wah College, School of Medical and Health Sciences, 98 Shantung Street, Mongkok, Kowloon, Hong Kong. Tel: +852-34686656, Fax: +852-37532106, E-mail: michaelkuo@twc.edu.hk

Received 2017 April 10; Accepted 2017 August 02.

\section{Dear Editor,}

The event-related potential (ERP) technique, having a millisecond temporal resolution, is appropriately suited for the precise measurement of the electrical activities in the brain that are a direct result of cognitive processes. While a number of ERP investigations on episodic memory formation have been conducted in schizophrenia, they have tended to focus on the aspect of retrieval mechanisms $(1,2)$. There is only 1 ERP study, to the best of my knowledge, that examined episodic encoding.

The recent investigation by Green, Fitzgerald, Johnston, Nathan, Kulkarni, and Croft (3) investigated the relative contribution of early perceptual and late cognitive processes to episodic memory encoding impairment in schizophrenia using a subsequent memory paradigm. The subsequent memory effect (area between subsequent recognized and forgotten lines; see Figure 1) has consistently appeared at about $400 \mathrm{~ms}$ post-stimulus onset, especially when the encoding condition required a deeper processing $(4,5)$. Their participants employed a semantic strategy by categorising words as pleasant or unpleasant. Their results indicated that early perceptual processes are intact in schizophrenia while deficits in higher order cognitive processes at encoding contributed to episodic memory impairments. Their results at later time windows fit well with the fMRI studies as frontal lobes were identified as a key substrate for generating these ERPs (6-8). The study by Green, Fitzgerald (3) is important because it specifically examined episodic encoding and the results showed potential cognitive processes that deficits are likely to be identified.

Since this is the only investigation that focused on encoding to episodic memory, it is still unclear whether results in the early and later processes may be influenced and whether there is electrophysiological evidence that memory deficits in people with schizophrenia may be mitigated by different encoding strategies. In addition, in the study by Green, Fitzgerald (3) there is no baseline condition in
Figure 1. Typical SME

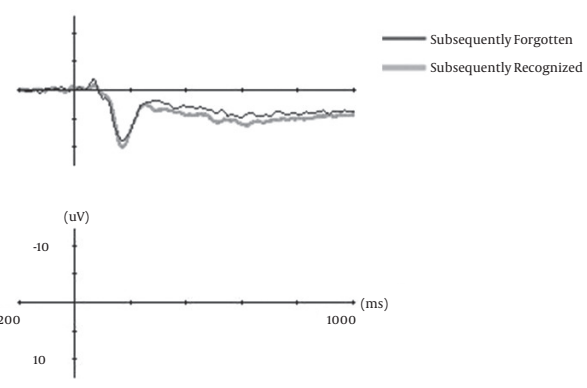

The effect is the area between subsequent recognized and forgotten lines. Subsequently recognized ERP is typically more positive-going.

which encoding strategy is employed. Without this condition, it is not possible to examine whether strategies are of any benefit to people with schizophrenia. Future studies using a similar technique may consider these points.

Memory is a central cognitive function, which supports an individual's daily function. Professionals in the rehabilitation field typically help people with memory deficits to cope with this problem by compensatory approaches that support the retrieval of stored information (9). Intervention is under-developed for modulating the encoding process and, even if it is available, it might not be appropriate to apply directly to people with schizophrenia. The potential deficits revealed in the encoding processes identified from SMEs will contribute to the design of memory remediation programs in the future.

\section{Footnote}

Financial Disclosure: Acknowledgements 


\section{References}

1. Guillaume F, Guillem F, Tiberghien G, Stip E. Mismatched expressions decrease face recognition and corresponding ERP old/new effects in schizophrenia. Neuropsychology. 2012;26(5):568-77. doi: 10.1037/a0028924. [PubMed: 22686352].

2. Guillaume F, Stip E, Tiberghien G. About the nature of contextual impairments revealed by FN400 abnormalities in schizophrenia. Front Hum Neurosci. 2013;7:60. doi: 10.3389/fnhum.2013.00060. [PubMed: 23460768].

3. Green AE, Fitzgerald PB, Johnston PJ, Nathan PJ, Kulkarni J, Croft RJ. Evidence for a differential contribution of early perceptual and late cognitive processes during encoding to episodic memory impairment in schizophrenia. World J Biol Psychiatry. 2017;18(5):369-81. doi: 10.1080/15622975.2016.1208839. [PubMed: 27573041].

4. Kuo MCC. Intentional Encoding in Elderly Adults: An Event-Related Potential Study. Arch Neurosci. 2016;3(4)
5. Kuo MC, Liu KP, Ting KH, Chan CC. Age-related effects on perceptual and semantic encoding in memory. Neuroscience. 2014;261:95106. doi: 10.1016/j.neuroscience.2013.12.036. [PubMed: 24374080].

6. Cansino S, Trejo-Morales P, Hernandez-Ramos E. Age-related changes in neural activity during source memory encoding in young, middleaged and elderly adults. Neuropsychologia. 2010;48(9):2537-49. doi: 10.1016/j.neuropsychologia.2010.04.032. [PubMed: 20441775].

7. Kuo MC, Liu KP, Ting KH, Chan CC. Differentiation of perceptual and semantic subsequent memory effects using an orthographic paradigm. Brain Res. 2012;1486:82-91. doi: 10.1016/j.brainres.2012.10.005. [PubMed: 23063888].

8. Weyerts H, Tendolkar I, Smid HG, Heinze HJ. ERPs to encoding and recognition in two different inter-item association tasks. Neuroreport. 1997;8(7):1583-8. [PubMed: 9189896].

9. Wilson BA, Emslie H, Quirk K, Evans J, Watson P. A randomized control trial to evaluate a paging system for people with traumatic brain injury. Brain Inj. 2005;19(11):891-4. [PubMed: 16296571]. 